\title{
THE EFFECT OF SURFACE ROUGHNESS ON THE SOIL LOSS
}

\author{
Khalid F. Hassan
}

Soil and Water Sci. Dept., College of Agri. and Forestry, Mosul Univ., Iraq.

\begin{abstract}
Field measurements and lab analysis were conducted to determine the effect of soil surface roughness ( oriented and random) resulted from discing and chiseling on the soil loss by wind erosion. Some soil ridges parameters were measured in the field and aggregation (clods and non-erodible aggregates) were determined in the lab. The soil loss of the two operations was determined as a function of these variables. The results showed that the large proportions of random roughness(large clods) and clear oriented roughness (soil ridges) in the tilled layer after soil discing have a greatest effect in reducing the amount of soil loss and potential erosivity of soil by wind action in comparison with soil chiseling.This is attributed to the fact that the soil clods easily crushed into fine aggregates after soil chiseling but remained unchanged in soil discing. The statistical analysis coming in agreement with the results of the lab and field investigation
\end{abstract}

\section{INTRODUCTION}

The objective of primary and secondary tillage for wind erosion control is to produce rough and cloddy surfaces which have a greatest effect in reducing erosion by sheltering and trapping the blown soil particles and decreasing the wind velocity near the rough surface ( Hofman and Franzen, 1997). In other word, for any given soil conditions the amount of soil which will be blown depends on the two factors; the prevailing wind velocity and the roughness of soil surface (Romken et. al. 2001). An empirical-logarithmic formula suggested by Kirkby and Morgan(1987) for the relationships showed that;

$$
\mathrm{Z}=0.81(\log 5.5 \mathrm{ds})
$$

$\mathrm{Z}=$ The height above erodynamic surface at which the wind velocity =zero

$\mathrm{ds}=$ Grain or aggregate diameter $(\mathrm{mm})$

The value of $\mathrm{Z}$ was varied with the logarithemic of grain or aggregate diameter, therefore the $\mathrm{Z}$ value over rough surface was greater than that of smooth surface. For this reason the height of soil surface during the measuring processes should be corrected due to changes in height of reading it made(Gomez ,2005). Many researchers have reported that the disc and chisel are the most common tools used to roughen the soil and bring clods to surface for wind erosion control and reducing soil loss (Saleh, 1997, Hofman and Franzen, 1997), but other workers mentioned that tillage in general can gradually reduces the soil surface roughness by breaking the clods and aggregates that resist wind erosion( USDA,2008). Surface roughness is very important factor when measured the total soil loss from a given field. Woodruf and Siddaway (1965) have developed an empirical equation for estimation the erodibility of soils. The wind erosion equation (WEE) developed by these workers estimate a potential erosion in ton/acre as a function of five independent variables. This equation is ; 
Received 3/1/2010 accepted 21/6/2010 


$$
\begin{aligned}
& A=f(I, K, C, L \text { V }) \\
& \text { (2) } \\
& \mathrm{A}=\text { Soil loss } \mathrm{t} / \mathrm{acre} \\
& \mathrm{I}=\text { Soil erodibility factor } \\
& \mathrm{K}=\text { Soil roughness factor } \\
& \mathrm{L}=\text { Unshelterd length factor } \\
& \mathrm{C}=\text { Climatic factor } \\
& \mathrm{f}=\text { function } \\
& \mathrm{V}=\text { Vegetation cover factor }
\end{aligned}
$$

Among the factors which help to protect soil from wind erosion, soil roughness factor(K-factor). Garcia et. al. (2008) have reported that K-factor estimates the fractional reduction of erosion caused by ridges and non-erodible aggregates. Therefore $\mathrm{K}$ has been divided into; soil ridge roughnesss sub-factor ( Krd) and soil random roughness sub-factor ( Krr),then;

$$
\mathrm{K}=\mathrm{Krd}+\mathrm{Krr}
$$

The objective of the study reported here ,was to provide an important informations on the interaction effect of random roughness (aggregation) and oriented roughenss (soil ridges) resulted from soil discing and chiseling (which are widely used operations in agricultural dryland farms at northern Iraq) on the soil loss by wind action, and to compare the profitibility of the two operations under this condition in order to indicate areas where further researches are needed.

\section{MATERIALS AND METHODS}

The study was conducted on the selected farm located at Kaber Al- Abid area (about $20 \mathrm{Km}$ south Mosul city). Table (1) showing some physical, chemical characteristics and classification of studied farm's soil. Composite surface soil samples ( $0-25 \mathrm{~cm}$ in depth ) was taken from tilled layer after discing and chiseling. This depth selected because many field observations indicated marked soil structural differences occurred approximately within this depth.

Table( 1 ): Selected characteristics of studied farm's soil

\begin{tabular}{|c|c|c|c|c|c|c|c|c|}
\hline Clay & Silt & Sand & \multirow{2}{*}{ Texture } & \multirow{2}{*}{$\mathrm{pH}$} & $\mathrm{EC}$ & $\mathrm{OM}$ & $\mathrm{CaCO} 3$ & \multirow{2}{*}{ Classification } \\
\cline { 2 - 2 } & $\mathrm{gm} / \mathrm{kg}$ & & & $\mathrm{dS} / \mathrm{m}$ & \multicolumn{2}{|c|}{$\mathrm{gm} / \mathrm{kg}$} & \\
\hline 372 & 367 & 261 & Silty Clay & 7.7 & 0.44 & 9.8 & 288 & Entisol \\
\hline
\end{tabular}

The soil samples were air- dried and gently crushed to pass through a 4 sieves. Dry sieving for four fractions $(2,1,0.50$, and $0.25 \mathrm{~mm})$ were done according to the procedure mentioned by Kemper and Rosenau (1986). Samples were sieved two times. The accumulated percentage of soil aggregates passing through each sieve was substitute in the following equation to calculate the Arithmetic Mean Size (AMS) for each soil treatment as reported by Emond ( 1971);

$$
\begin{gathered}
1400 \text { - }(\mathrm{Y} 1+3 / 2 \mathrm{Y} 2+3 \mathrm{Y} 4+8 \mathrm{Y} 8) \\
400
\end{gathered}
$$


Where;

$\mathrm{Y} 1=$ soil aggregates passing through $0.25 \mathrm{~mm}$ sieve.

$\mathrm{Y} 2, \mathrm{Y} 4$ and $\mathrm{Y} 8=$ the accumulated percentage of aggregates passing through $0.50,1.0$, and $2.0 \mathrm{~mm}$ sieves respectively

The standard dry sieving procedure repeated by resieving the non erodible aggregates (NEA) expressed as percent larger than $0.84 \mathrm{~mm}$ in diameter.The obtaining values were plotted on the table ( 2 ) to obtaining the soil erodibility factor( I ) of wind erosion equation (WEE).

Table ( 2 ): Soil erodibility factor( I ) in $\mathrm{Mg} / \mathrm{ha}$. as a function of $\%$ NEA.

\begin{tabular}{|c|c|c|c|c|c|c|c|c|c|c|}
\hline \multirow{2}{*}{ Percent } & \multicolumn{10}{|c|}{ Unit } \\
\cline { 2 - 12 } & 0 & 1 & 2 & 3 & 4 & 5 & 6 & 7 & 8 & 9 \\
\hline 0 & - & 694 & 560 & 493 & 437 & 403 & 378 & 356 & 335 & 315 \\
\hline 10 & 300 & 292 & 285 & 278 & 270 & 262 & 254 & 245 & 236 & 228 \\
\hline 20 & 220 & 213 & 206 & 200 & 195 & 190 & 185 & 180 & 175 & 170 \\
\hline 30 & 166 & 162 & 158 & 154 & 150 & 146 & 142 & 138 & 134 & 130 \\
\hline 40 & 126 & 122 & 118 & 114 & 111 & 108 & 104 & 99 & 94 & 89 \\
\hline 50 & 84 & 79 & 74 & 69 & 65 & 61 & 57 & 54 & 52 & 49 \\
\hline 60 & 47 & 45 & 43 & 41 & 39 & 37 & 35 & 33 & 31 & 29 \\
\hline 70 & 27 & 25 & 22 & 19 & 16 & 13 & 10 & 7 & 6 & 5 \\
\hline 80 & 4 & - & - & - & - & - & - & - & - & - \\
\hline
\end{tabular}

In addition, the study was extended to measure directly in the field the following parameters of soil surface roughness; the maximum peak height (MPH), maximum depression depth (MDD), peak roughness frequency (PRF), and peak roughness frequency to peak roughness height ratio (PRF/PRH) and tortuosity (TOR) which is the ratio between actual peak roughness height and project (on the horizontal plane ) of profile of the soil surface( Saleh, 1997). Peak roughness heights (PRH) were measured ten-times in various farm directions using measuring ruler to obtain the mean peak ridge height which plotted on non-linear measure curve of roughness (fig 1) to obtaining the equivalent soil roughness factor $(\mathrm{K})$. The curve was based on a design wind velocity of $50 \mathrm{mile} / \mathrm{hr}$ at $50 \mathrm{ft}$ height with wind direction at 45 degree to field(Woodruf and Siddoway 1965,Lehrsch et. al. 1988.).

$$
\mathrm{E}=\mathrm{f}(\mathrm{I} * \mathrm{~K})
$$

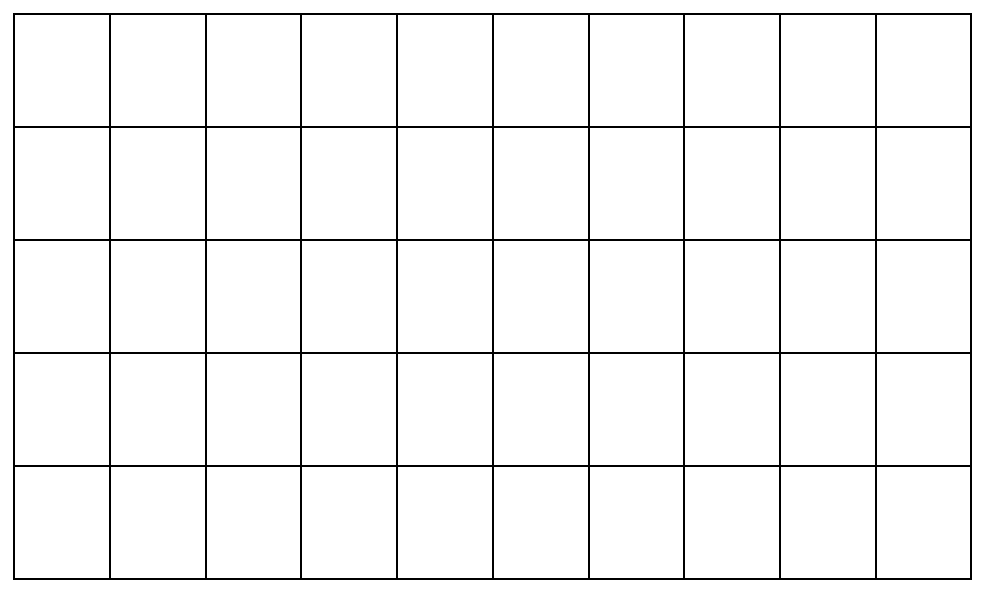




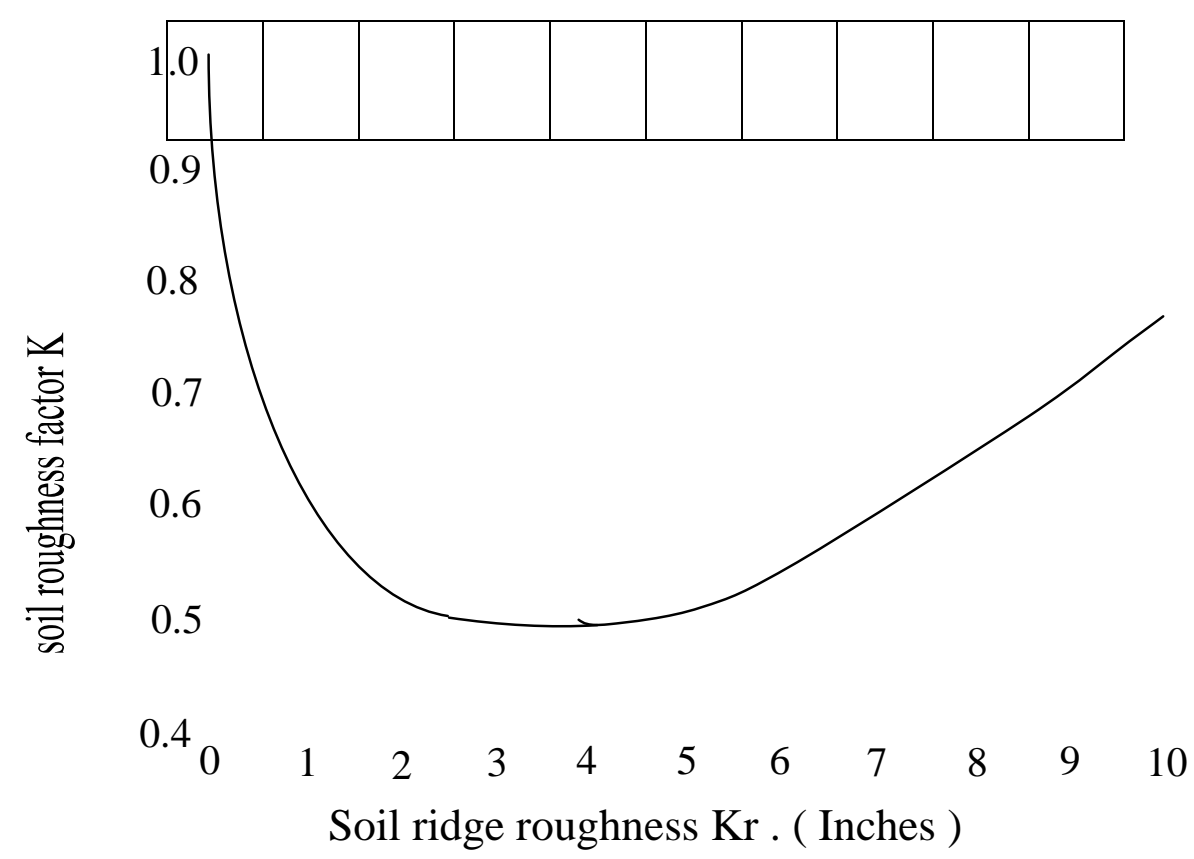

Fig.1.Soil roughness factor $\mathrm{K}$ as a function of soil ridge factor Krd

The $\mathrm{K}$ factor in the wind erosion equation (WEE) is a soil roughness factor which dose not include the random roughness. The potential average annual soil loss by wind (E) was calculated as a function of soil erodibility factor ( I ) and soil roughness factor $(\mathrm{K})$ therefore; The comparison between the two operations (discing and chiseling) was done statistically by obtaining the Coefficient of Creation (CC) for each tool using the following logarithmic equation (Steel and Torri ,1980);

$$
\begin{aligned}
& \mathrm{CC}=\frac{\log \mathrm{Y} 1-\log \mathrm{Y} 2}{\log \mathrm{X} 1-\log \mathrm{X} 2} \\
& \mathrm{Y} 2=\text { the higher and lower measured values of the } \mathrm{K} \text { factor after soil } \\
& \text { tilled. }
\end{aligned}
$$

Where;

$\mathrm{X} 1$ and $\mathrm{X} 2=$ the higher and lower measured values of the $\mathrm{K}$ factor before soil tilled .

The relations between potential soil loss (E) - soil erodibility factor ( I ) and potential soil loss (E) - soil erodibility factor( I ) * soil roughness factor (K) for each tool were analyzed statistically using the regression analysis. All statistical analysis were run on SAS software.

\section{RESULTS AND DISCUSSION}

The following discussion of soil surface roughness (SSR) include the interaction of random roughness (aggregation) and oriented roughness (soil ridges) on the soil loss. Aggregate size distribution (random roughness) of studied soil field ( as shown in table 3 ) indicated that the soil chiseling was more effected and resulted in fewer aggregates than discing. The soil chiseling operation resulted of $28.54 \%$ in $0.50-0.25 \mathrm{~mm}$ size range and more $27.16 \%$ in discing up to $2.0 \mathrm{~mm}$ in size. 
Table. ( 3 ): \% Aggregate size distribution $(<2)$ after discing and chiseling .

\begin{tabular}{|c|c|c|c|c|c|}
\hline Treatments & $2-1 \mathrm{~mm}$ & $1-0.5 \mathrm{~mm}$ & $0.50-0.25 \mathrm{~mm}$ & $<0.25 \mathrm{~mm}$ & AMS $(\mathrm{mm})$ \\
\hline Discing & 27.16 & 24.40 & 33.68 & 14.62 & 0.74 \\
\hline Chiseling & 20.82 & 22.28 & 28.56 & 26.54 & 0.61 \\
\hline
\end{tabular}

This variation may be attributed to the fact that the aggregates easily crushed by soil chiseling into fine aggregates of less than $0.50 \mathrm{~mm}$ in comparison with soil discing, which aggregates remained, unchanged. This result led us that the AMS of soil chiseling was less than that of soil discing .The AMS were $0.74 \mathrm{~mm}$ and $0.61 \mathrm{~mm}$ for discing and chiseling treatments respectively. From the physical view, this variation was not significant because the AMS values of the both operations are identical with that of sand particles. The soil aggregates (random roughness) of more than $2 \mathrm{~mm}$ in diameter in the $1^{\text {st }}$ sieving for both operations were reduced in the $2^{\text {nd }}$ sieving. (Table 4).This mean that the continuous soil discing and chiseling will minimize the size range of soil aggregates to the limit which easily eroded by wind. For this reason the expected AMS value in the $2^{\text {nd }}$ sieving will be less than that of $1^{\text {st }}$ sieving for both operations

Table(4):Sand-size aggregate distribution $\%$ after for 1 st and $2^{\text {nd }}$ sieving produced by the two operations

\begin{tabular}{|c|c|c|c|c|}
\hline \multirow{2}{*}{ Treatments } & \multicolumn{2}{|c|}{$1^{\text {st }}$ sieving } & \multicolumn{2}{c|}{$2^{\text {nd }}$ sieving } \\
\cline { 2 - 5 } & $>2 \mathrm{~mm}$ & $<2 \mathrm{~mm}$ & $>2 \mathrm{~mm}$ & $<2 \mathrm{~mm}$ \\
\hline Discing & 51.60 & 48.40 & 40.95 & 59.17 \\
\hline Chiseling & 45.10 & 73.09 & 19.74 & 80.26 \\
\hline
\end{tabular}

On the other hand, the soil surface roughness (SSR) increases as the proportion of NEA in the tilled layer increases. The proportion of NEA after discing and chiseling are $46.15 \%$ and $33.85 \%$ respectively. The more NEA \% resulted from soil discing, the greater will be the volume of the non- erodible projection at the surface of the soil and the less the amount of soil loss that will occur, in comparison with soil chiseling. Other parameters described oriented roughness (as present in table 5) showed that the resulted roughness from soil discing has a high values in comparison of soil chiseling. This variation attributed to the primary effects of random roughness which also raised the tortuosity of tilled soil layer and made slight differences between the two operations.

Table(5):Selected roughness parameters of soil discing and chiseling operations

\begin{tabular}{|c|c|c|c|c|c|c|c|}
\hline \multirow{2}{*}{ Treatment } & & MPH & MDD & PRH & \multirow{2}{*}{ PRF } & \multirow{2}{*}{$\mathrm{PF} / \mathrm{PH}$} & \multirow{2}{*}{ TOR } \\
\hline & NEA\% & & $\mathrm{Cm}$ & & & & \\
\hline Discing & 46.15 & 18.1 & 9.10 & 20.4 & 4 & $1 / 2.6$ & 0.71 \\
\hline Chiseling & 33.85 & 12.1 & 6.66 & 15.9 & 5 & $1 / 2.5$ & 0.66 \\
\hline
\end{tabular}

In order to determine the total effectiveness of K-factor ( $\mathrm{Krd}+\mathrm{Krr})$, the NRCS(2002), has reported that the Krr sub-factor for random roughness value 
which has been used to estimate the soil loss by WEE will be determined from table (6) .The Krr sub -factor for random roughness has been devloped for various level of soil erodibility index( I )values ( table 6).The extracted values of Krr has been added to Krd (which is obtained from fig.1) to account the soil roughness factor(K)..

Table(6):Krr values for Peak roughness height (PRH) and I-factor(NRCS 2002)

\begin{tabular}{|c|c|c|c|}
\hline Ridge height $(\mathrm{Cm})$ & $\mathrm{I}=104$ & $\mathrm{I}=86$ & $\mathrm{I}<56$ \\
\hline 5 & 1.00 & 1.00 & 1.00 \\
\hline 10 & 0.95 & 0.86 & 0.70 \\
\hline 15 & 0.88 & 0.76 & 0.51 \\
\hline 20 & 0.82 & 0.68 & 0.40 \\
\hline 25 & 0.78 & 0.62 & 0.34 \\
\hline 30 & 0.74 & 0.57 & 0.30 \\
\hline 35 & 0.72 & 0.54 & 0.27 \\
\hline 40 & 0.69 & 0.51 & 0.24 \\
\hline
\end{tabular}

From this table, emergency tillage can be done on soils have been an I-factor $>104 \mathrm{Mg} / \mathrm{ha}$ (Garcia et al 2008). For this reason the ridge height (oriented roughness) at right of prevailing wind direction and with space rate of 1:4 resulted from soil discing $(20.4 \mathrm{~cm})$ is more than that of soil chiseling $(15.9 \mathrm{~cm})$. This variation in ridge height reflect the mechanism of each tool in producing a rough surface .

The potential soil loss(E) by wind in both operations are calculated and presented in table(7). When soil erodibility factor ( I) is $104,154 \mathrm{Mg}$ / ha and roughness height are $20.4,15.1 \mathrm{~cm}$, the Krr values (as shown in table 6) are 0.82 and 0.88 for soil discing and chiseling respectively. Therefore, the potential erosivity( E ) of soil by wind action $\{\mathrm{E}=\mathrm{f}[\mathrm{I} *(\mathrm{Krd}+\mathrm{Krr})]\}$ was $14.27 \mathrm{Mg} / \mathrm{ha}$ for soil discing and was $22.79 \mathrm{Mg} /$ ha for chiseling (table 7).

Table( 7 ): Soil loss E as a function of I and K (Krd+Krr) of the both operations

\begin{tabular}{|c|c|c|c|c|c|}
\hline Treatment & $\mathrm{I}$ & $\mathrm{Krd}$ & $\mathrm{Krr}$ & $\mathrm{K}$ & $\mathrm{E}=\mathrm{I} * \mathrm{~K}$ \\
\hline Discing & 104 & 0.55 & 0.88 & 0.143 & $104^{*} 0.143=14.27$ \\
\hline Chiseling & 154 & 0.65 & 0.82 & 0.148 & $154^{*} 0.148=22.79$ \\
\hline
\end{tabular}

This results coming in agreement with the results of statistical analysis. Linear regression were run on the potential soil loss( E ) - soil erodibility( I ) * soil roughness $(\mathrm{K})$. The best fitting regression equations are listed in table (8). The high values of both coefficient of determination $\left(\mathrm{R}^{2}\right)$ and coefficient of creation (CC) indicated that the two operations were highly correlated and the variations in $\mathrm{R}^{2}$ and $\mathrm{CC}$ values between the two operations were small. These results can be obtained from the fact concluded before, that the surface aggregation (random roughness) with high AMS and high elevation of soil ridges (oriented roughness) and tortuosity resulted a rough surface and less amount of soil loss.

Table $(8)$ : regression equations predicting soil loss $(\mathrm{E})=\mathrm{f}(\mathrm{I} * \mathrm{~K})$

\begin{tabular}{|c|c|c|c|c|}
\hline Treatment & \multicolumn{2}{|c|}{ regression equations } & R2 & $\mathrm{CC}$ \\
\hline Soil discing & $\mathrm{Ed}=7.54+0.061(\mathrm{I}$ & $+5.41(\mathrm{~K})$ & 0.91 & 1.71 \\
\hline Soil chiseling & $+0.074(\mathrm{I}$ & $+8.10(\mathrm{~K})$ & 0.97 & 1.55 \\
\hline
\end{tabular}


At the end we can concluded that the comparison of results obtained in the present study showed that soil surface roughness (SSR) is related to the single aggregation size classes and the most soil particles under these conditions spacialy the particles $>2 \mathrm{~mm}$ in diameter breakdown into fine particles which are easily eroded ( lost ) from field by wind action. Thus, temporal variability of soil surface roughness including aggregation and non-erodible soil fractions( $>0.84 \mathrm{~mm}$ in diameter) may be considered in soil researches in agricultural soils. Also frequent measures are needed and the resulting soil surface roughness (SSR) is short lived, because ridges can be filled and the roughens broken down by abrasion to produce a smooth surface susceptible to wind.

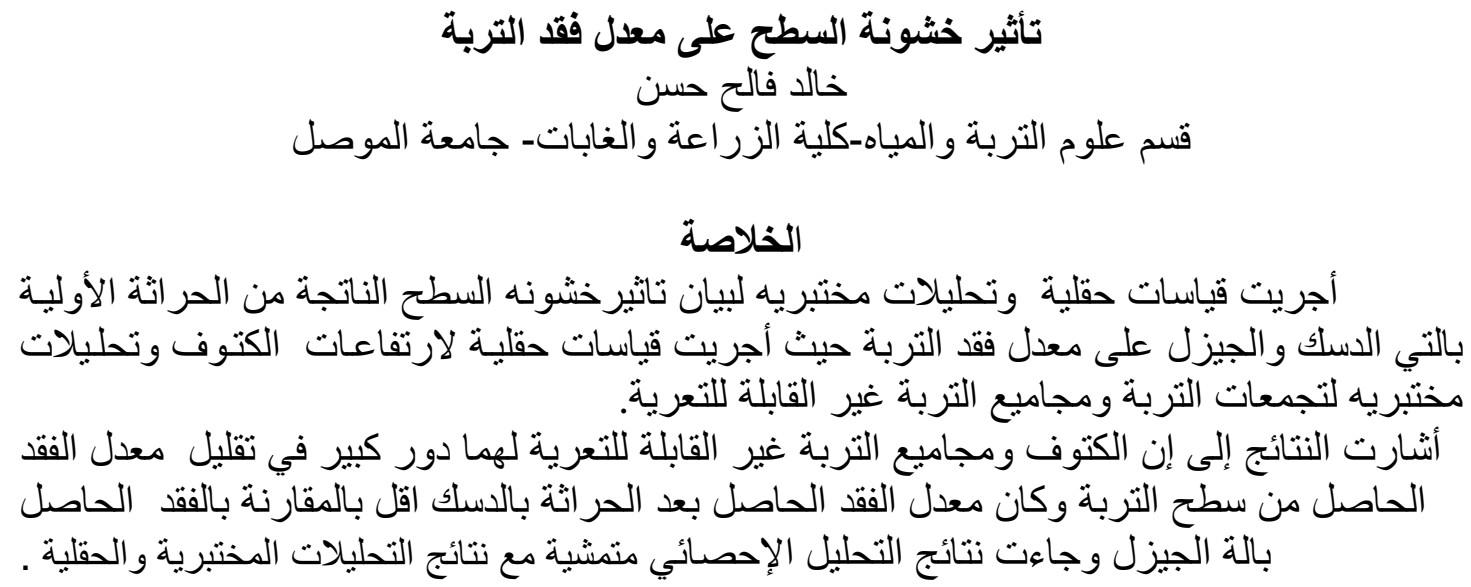

\section{REFERENCES}

Anonymous (2002) .Soil Roughness. (Natural Resources Conservation Service) Publ paper COD. 609 .June .USA.

Anonymous (2008).'Natural resources', Conservation Service Practice. Cod 609.USA

Emond, G.(1971).Effect of rotation, tillage treatment and fertilizers on the aggregation of clay soils. Can. J. Soil Sci. 51; 235 - 241

Garcia, R ., M. Alevarez ,A. Requijo and A. Tarquis (2008).Multifractal Analysis of soil surface roughness. Soil Sci.Soc.Am.677 Segoe. Rd.Madison, USA.

Gomez,J.A.,and, M.A. Nearing (2005).Runoff and sediments loss from a rough rough and smooth surface in laboratory experiment. Catena,59:253- 266.

Hofman, V. and D. Franzen, (1997). Emergency tillage to control wind erosion ND Agricultural Experiment Station, NDSU Extension Service. USA

Kemper, W.D., and Rosenau, (1986).Aggregate stability and distribution .in Klute ,Methods of Soil Analysis .Part 1 ,2nd ed . Am. Soc. of Agr. USA.

Kirkby, M. and R. Morgan. (1987). "Soil Erosion" A publication of British Geom Res. Group. John Willy and Son. ISBNO441.Great Britian.

Lehrsch, G.A.. and F.D. Whisler and M. M. Romkens (1988) .Spatial variation parameters describing soil surface roughness. Soil Sci.Soc. Am. J. 52:311-319.

Romken ,M. Helming, K., and Prasad , S .,(2001). Soil erosion under different surface roughness , and soil water regimes.Catena ,46;103-123. 
Saleh, A.,(1997) .Commen of chain method for measuring soil roughness. Soil Sci.Soc.Am.J.61:1532-1533.

Steel, B and J. Torri.(1980). Principles and Proceedures of Statistics. 2nd Ed. New New York. USA . 633p.

Woodruf. N. and F. Siddoway (1965). A wind erosion equation . Soil Sci Soc. Am. Am. Proc. 29; 469 - 481. 